\title{
Un ministro para la Defensa de la República desde el exilio: Juan Hernández Saravia
}

\author{
Manuela Aroca Mohedano
}

\begin{abstract}
RESUMEN:
La nueva situación internacional surgida tras el final de la ll Guerra Mundial propició la recuperación de las instituciones republicanas españolas en el exilio. Juan Hernández Saravia, un militar profesional, azañista y republicano, será el ministro de la Defensa Nacional de la República Española. Entre posibilidades reales y utopías, a caballo entre la defensa a ultranza de la legalidad y la protección de los movimientos clandestinos antifranquistas, en medio de las disensiones de los militares exiliados dispersos en varios continentes, discurrirá la actuación de un Ministerio que tendrá como objetivo principal la recuperación del ejército para la futura restaurada

\author{
ABSTRACT \\ A Minister in exile for the Republic \\ Defence: Juan Hernández Saravia \\ The new international situation \\ arisen after the end of the Second \\ World War led to the recovery of \\ Spanish Republic Institutions in \\ exile. Juan Hernández Saravia, an \\ army officer, republican and \\ adherent to Azaña, became the \\ National Defence Minister of \\ Spanish Republic. \\ Among real possibilities and utopia, \\ halfway between a vigorous legality \\ defence and the protection of \\ clandestine movements against \\ Franco's dictatorship, the main \\ objective of this Ministery was the \\ army recovery for the future \\ restoring Republic, but the early \\ Cold War shattered these prospects.
} República y que verá truncadas sus expectativas por la aparición en el panorama mundial de los primeros indicios de la Guerra Fría.

PALABRAS CLAVE:

- Hernández Saravia, Juan - Gámir Ulibarri, Mariano - Giral Pereira, José - Llano de la Encomienda, Francisco

- Maquis

- Militares exiliados

- Ministerio de Defensa de la

República en el exilio

- República en el exilio

- Resistencia española

- Unión Nacional Española (U.N.E.) 
El triunfo aliado en la II Guerra Mundial posibilitó la aparición de un nuevo panorama internacional que, como un viento de esperanza, recorrió los rincones del globo a los que habían ido llegando los republicanos españoles. Las tímidas maniobras de unión que se habían iniciado en los campos de internamiento franceses tras el final de la Guerra Civil fueron, en términos generales, infecundas. Los partidos republicanos se disgregaron con la salida de sus dirigentes a diversos puntos de América Latina y los partidos más izquierdistas no lograrían una cohesión mínima hasta fechas avanzadas del proceso bélico. El Partido Comunista, cuya cúpula dirigente se encontraba también dispersa entre la URSS y América, fue el primero en crear, a partir de 1941, un embrión organizativo ligado a la Resistencia en la Francia ocupada y con ramificaciones de tipo guerrillero en el sur -el maquiscuyo objetivo específico era la caída del régimen de Franco.

Conducido por el Partido Comunista, da comienzo en Francia un proceso de aglutinamiento de organizaciones y partidos obreros que arranca con una reunión en Toulouse el 7 de noviembre de 1942. UGT, CNT, comunistas, socialistas y republicanos sentarán las bases en esa reunión de la constitución de la Unión Nacional Española (U.N.E.) que, a partir de ese momento, liderará políticamente los movimientos de Resistencia y antifranquistas en Francia.

Paralelamente, en 1940, los partidos republicanos trataban desde México de cohesionar en una organización política, Acción Republicana Española (A.R.E.), a los supervivientes de los partidos republicanos - Izquierda Republicana, Unión Republicana y Partido Republicano Federal-. Pero la unión no poseía visos de coherencia: en ella no quisieron participar los republicanos nacionalistas y las diferencias afloraron desde los primeros encuentros. Por otra parte, la legalidad republicana, al inicio de la década de los cuarenta, estaba representada por el Gobierno nominal del doctor $\mathrm{Ne}$ grín en Londres y la Diputación Permanente de las Cortes en México. Pero su representatividad era, en el panorama internacional, mucho menos que simbólica. El desarrollo de la II Guerra Mundial, progresivamente favorable al triunfo aliado, hace considerar la necesidad de un pacto de unidad entre partidos que permitiera recuperar visos de representatividad en las instituciones españolas en el exilio. El 25 de noviembre de 1943, en una reunión en México a la que asistieron miembros de IR, UR, PSOE, ERC y ARC, se decidía la creación de la Junta Española de Liberación (J.E.L.)

A partir de ese momento, la actuación del exilio español tenía dos vertientes plenamente diferenciadas: una caracterizada por los intentos de acción militar y política, protagonizada por la U.N.E. y los movimientos del maquis en el sur de Francia, con centro en Toulouse, que aglutinará a un importante número de excombatientes del Ejército Popular y cuya acción más visible la constituyó la entrada en el Valle de Arán en octubre de 1944; y una organización de contenido estrictamente político, mucho más etérea, heredera de los restos de legitimidad, liderada por los partidos republicanos con 
la colaboración del maltrecho Partido Socialista y apoyada en los resortes del nuevo orden político mundial.

Prácticamente en solitario, sin el apoyo del núcleo organizativo comunista, la Junta Española de Liberación conseguía en la Conferencia de San Francisco, de abril de 1945, inaugurar una época de nuevas perspectivas para la República con la condena del Gobierno de Franco en la Carta Fundacional de la O.N.U. San Francisco, en primer lugar, y Potsdam, más tarde, abrían nuevas posibilidades a la República. La reconstitución de la legalidad y las instituciones republicanas eran los primeros pasos a acometer para recoger aquellos vientos favorables. A ello se aprestaron los miembros de la comunidad política republicana en el exilio. Pero, desde aquellos primeros momentos, quedaba al margen la opción que había protagonizado el Partido Comunista en Francia y se repetían los episodios de desunión que se habían vivido en la Guerra Civil. Sólo desde el punto de vista de la organización militar - siempre teórica- se produjeron algunos contactos entre ambas opciones antifranquistas.

Los vientos favorables fueron aprovechados para ejecutar la reconstrucción de las instituciones en el exilio: el 17 de agosto de 1945 se reunía en sesión extraordinaria la Cámara de los Diputados en México y proclamaba a Diego Martínez Barrio presidente de la República. Juan Negrín presentaba su dimisión y el nuevo presidente encargaba al doctor Giral la formación de un nuevo Gobierno.

\section{JUAN HERNÁNDEZ SARAVIA, MINISTRO DE DEFENSA NACIONAL.}

Cuatro miembros de Izquierda Republicana -José Giral, como presidente del Gobierno, y Álvaro de Albornoz, Manuel Torres y Augusto Barcia, como ministros- dos miembros de la CNT - Horacio Martínez y José Expósito-, uno del PSOE - Fernando de los Ríos-, un ministro de Ezquerra Republicana de Cataluña - Miguel Santaló-, un miembro de UGT -Trifón Gómez- y uno de Acción Republicana de Cataluña -Luis Nicolau d'Olwer-, constituían, junto a los dos miembros independientes Juan Hernández Saravia y Ángel Ossorio y Gallardo- el nuevo Gobierno dirigido por José Giral' .

Entre los miembros que carecían de filiación política se encontraba el ministro de Defensa Nacional de la República, el general Juan Hernández

' La constitución del Gobierno de la República en el exilio ha sido examinada en profundidad por Sonsoles Cabeza y Alicia Alted y puede ser consultada en ALTED, Alicia. «Ayuda humanitaria y reorganización institucional en el exilio", en CUESTA, Josefina y BERMEJo, Benito (coords.), Emigración y exilio: españoles en Francia: 1936-1946, Madrid, Eudema, 1996 y CABEZA SÁnCHEZ-Albornoz, Sonsoles, Historia política de la Segunda República en el exilio, Madrid, Fundación Universitaria Española, 1997. 
Saravia, a quien José Giral encomendó una de las tareas con mayor contenido práctico con vistas a la «inminente» recuperación de la República: el reagrupamiento y ordenación del ejército disperso en el exilio. No era la primera vez que José Giral reclamaba la colaboración de Juan Hernández Saravia en momentos decisivos. Lo había hecho también en los días que siguieron a la rebelión, nombrándole ministro de la Guerra el 5 de agosto de 1936. José Giral admiraba, desde mucho tiempo atrás, el conocimiento del ejército y la capacidad organizativa de Juan Hernández Saravia.

Juan Hernández Saravia pertenecía al grupo de militares de confianza de Manuel Azaña y, durante años, ejerció como su primer ayudante y lugarteniente en el Ministerio de la Guerra ${ }^{2}$. Había iniciado su carrera militar con el ingreso en la Academia de Artillería de Segovia en julio de 1898 dentro de los presupuestos militares más convencionales, participando en algunas campañas africanas como la recuperación de territorios en Marruecos posterior al desastre de Barranco del Lobo en 1909 y la que siguió, en 1921, al desastre de Annual. Sin embargo, en líneas generales, su carrera se había desarrollado dentro de la formación teórica que le proporcionaban sus destinos en las guarniciones peninsulares.

Fueron pocos sus encontronazos con el régimen de la Restauración, a pesar de la delicada y decisiva situación por la que atravesó el ejército en el primer cuarto del siglo XX, hasta que el conflicto artillero, en 1926, le llevó definitivamente al republicanismo. Ya había sentido la tentación de la disidencia cuando conoció, meses antes, la organización del pronunciamiento militar preparado para el día de San Juan del año 1925. Y sin embargo, fue la actitud personal de Alfonso XIII la que llevó a Juan Hernández Saravia al republicanismo. El rey había prometido a la comisión de artilleros a la que pertenecía Saravia no firmar el célebre decreto preparado por su primer ministro, Primo de Rivera, para anular el sistema tradicional de ascensos por antigüedad que regía en el Arma de Artillería. Pero lo hizo, y su gesto desencadenó un movimiento irreversible dentro del ejército: la retirada del apoyo artillero a la Dictadura y a la Monarquía. Para Juan Hernández Saravia el gesto traspasó la cuestión legal para convertirse en una cuestión de honor que le situó definitivamente del lado de la República.

Es cierto que por aquella época ya había conocido al personaje que tendría una mayor influencia vital y política en su vida, Manuel Azaña, pero su llegada al republicanismo arrancó de una problemática concreta y de una concepción esencialmente militar: una cuestión de honor. A partir de ese momento, se convirtió en un destacado adversario de la Dictadura y la Mo-

${ }^{2}$ El presente estudio forma parte de una tesis doctoral en elaboración, dirigida por la profesora Ángeles Egido León, que abarca el estudio biográfico completo del general Juan Hernández Saravia, enmarcado en el análisis del papel que representó el ejército profesional republicano en el advenimiento, consolidación y desaparición de la II República. 
narquía, ocupando puestos de responsabilidad en la rebelión desde la clandestinidad y la separación efectiva del ejército ${ }^{3}$, hasta que la proclamación de la República le condujo al desempeño de tareas de responsabilidad dentro de la organización del ejército. Desempeñó el puesto de jefe del Gabinete Militar de Azaña durante el primer bienio de la República, y fue en esa tarea donde adquirió un profundo conocimiento de los entresijos del ejército y de la problemática que ocasionaría el intento de democratización y reestructuración de un cuerpo que, con enormes contradicciones a lo largo del siglo, había sido protagonista y víctima, a la vez, de la situación política en el período de la Restauración.

Su amistad y colaboración con Manuel Azaña continuó durante todo el período de existencia de la República. En 1936 fue su secretario particular hasta que el alzamiento militar le apartó de su colaboración directa con el presidente de la República y dirigió, desde su puesto destacado en la Unión Militar de Republicanos Antifascistas (U.M.R.A.), la toma de todos los puntos clave en el ministerio de la Guerra con el objetivo de hacer fracasar el pronunciamiento militar. En agosto de 1936, José Giral le ofrecía el puesto de ministro de la Guerra que ya venía ocupando en la práctica desde julio ${ }^{4}$. Fue ministro durante un corto período de tiempo. Dimitió junto al resto de los miembros del Gobierno Giral en septiembre del mismo año, pero su actuación fue decisiva en el planteamiento teórico del futuro del ejército popular.

A partir de ese momento, prestó servicio a la República en los estrictos límites de su carrera militar: dirigió el sector de Córdoba en el último período de 1936, fue director de la Defensa Especial Contra Aeronaves (D.E.C.A.), se puso al frente del Ejército de Levante en la efímera victoria sobre Teruel, y fue, en la recta final de la guerra, jefe del Grupo de Ejércitos de la Región Oriental, puesto desde el cual coordinaba a los Ejércitos del Ebro y del Este y desde el que se enfrentó a dos momentos claves en la guerra civil: la Batalla del Ebro y la pérdida de Cataluña.

Tras la caída de Barcelona, cruzó la frontera con Francia y se instaló con su familia en un pequeño pueblo cercano a Marsella, Eguilles, donde sobrevivió con la ayuda económica de la Junta de Ayuda a los Refugiados Españoles (J.A.R.E.) y los trabajos ocasionales de sus hijas mayores, hasta que la ocupación alemana de todo el territorio francés en 1942 le llevó a intentar el traslado a México desde Marsella, traslado que no pudo producirse por la

\footnotetext{
${ }^{3}$ En agosto de 1927, a petición propia, pide su pase a supernumerario sin sueldo después de haber tenido problemas legales importantes tras su participación en el movimiento artillero y de haber sido perseguido por la animadversión personal que concibió contra él Miguel Primo de Rivera. AGMS, Sección Primera, Legajo E-736, Expediente militar de Juan Hernández Saravia, hoja manual de servicios de 1927.

${ }^{4}$ El general Castelló había sido nombrado ministro en julio, pero una enfermedad mental le impidió afrontar su cargo y Juan Hernández Saravia dirigió, en la práctica, el funcionamiento del Ministerio en aquellos difíciles primeros momentos de la guerra.
} 
negativa de las autoridades francesas de Vichy que nunca le concedieron el permiso. En Marsella vivió los momentos más duros de la Segunda Guerra Mundial y, con algunas amenazas para su seguridad, aguantó en los límites de la precariedad económica, compartiendo casas y pensiones para españoles, hasta que los nuevos tiempos que siguieron al triunfo aliado en la guerra mundial le abrieron la última oportunidad política de su vida: el Ministerio de Defensa de la República Española en el exilio.

\section{LA INSTITUCIONALIZACIÓN: EL GOBIERNO EN MÉXICO Y LA OPOSICIÓN DE ROJO Y LOS NEGRINISTAS AL MINISTERIO DE SARAVIA}

El nuevo Gobierno tuvo su sede inicialmente en México, donde se desplazaron los ministros que habitaban fuera del país, entre los cuales se encontraba Juan Hernández Saravia. Saravia dejó a su familia en Marsella y llegó a México D.F. a mediados de octubre de 1945, donde se instaló en casa de su amigo Santos Martínez Saura, en plena ebullición de las renovadas esperanzas que en aquel país se abrían para la comunidad republicana.

Centrada su actuación en la actitud internacional ante el Gobierno de Franco, comenzó la andadura del Gabinete Giral. Oficialmente, Negrín hizo declaración de obediencia y lealtad al Gobierno recién constituido, pero los círculos de sus seguidores plantearon una problemática ideológica que, en última instancia, no era más que una prolongación de las disensiones que se habian vivido en el bando republicano durante el último perícdo de la guerra civil. Estas divergencias alcanzaron una dimensión especialmente representativa en lo relativo a las cuestiones militares.

Los círculos militares fueron los primeros en acusar la diversidad de opiniones respecto al camino a seguir. Para los militares cercanos a Negrín, liderados dentro del ejército por Vicente Rojo desde Cochabamba en Colombia, antes de la configuración de la nueva situación política era evidente que la única acción viable era la sostenida por la U.N.E. y su intento de penetración en los Pirineos ${ }^{5}$. La formación de un Ministerio para los asuntos militares dirigido por Juan Hernández Saravia molestó profundamente a los negrinistas encabezados por el general Rojo que opinaban que su elección no representaba la deriva que el ejército había seguido en el fin de la guerra y dejaba fuera de la representación al Partido Comunista que había sido el verdadero ejecutor de

\footnotetext{
${ }^{5}$ «Si he mostrado mis simpatías por la J. de U.N. (su programa y sus fines) y si no oculto mis deseos de actuar en los Pirineos o donde sea es porque no dudo que una acción vigorosamente realizada y dirigida es lo único que puede darnos la solución", en Archivo Histórico Nacional, Sección Diversos, Archivo del general Rojo, Caja 41, Carpeta 4, Carta de Vicente Rojo a D. Julián Henríquez Caubín, desde México, el 11 de enero de 1945.
} 
la construcción del Ejército Popular 6 . Sin embargo, siguiendo el consejo de Juan Negrín, acataron la legitimidad del nuevo ministro.

En estas circunstancias, con anterioridad a la llegada de Saravia a México D.F. y por instrucciones expresas de éste, el Gobierno emitía una declaración que prohibía la participación de los militares en actividades políticas y obligaba a la disolución de las asociaciones de carácter militar que se habían organizado en el exilio. La Asociación de Militares Españoles Republicanos, con residencia en México y en La Paz, se disolvía para acatar lo establecido por el nuevo Gobierno, constituyéndose en unidad militar. En cambio, la U.M.R.A. no se disolvió y la C.M.R.E. tampoco lo hizo, amparándose esta última en su contenido de asociación cultural. La propia asociación disuelta pretendió transformarse en una asociación para la recuperación de la cultura militar, lamentándose alguno de sus miembros de que se hiciera sin esperar la llegada a México del ministro, Juan Hernández Saravia, con quien hubiera debido consultarse la conveniencia de tal decisión?.

A pesar de las dificultades de conciliación que ofrecía la nueva andadura política, el otoño de 1945 supuso una revitalización en todos los terrenos de la actividad de los republicanos en el exilio, paralela a la organización de los rudimentos de la nueva legalidad. Las primeras órdenes y decretos del ministro de Defensa llegaban en noviembre de 1945, desde la capital mexicana, y diseñaban un plan de actuación básico, en el cual resultaba fundamental la creación de un esqueleto de organización ministerial y la elaboración de un censo de militares en el exilio sobre el cual se iría configurando el futuro ejército de la República.

En contraposición al contenido político que exhibían las actuaciones de los Ministerios recién constituidos, el carácter del Ministerio de Defensa pretendía ser eminentemente práctico: crear y formar un ejército capaz de hacerse cargo de la defensa de la República, una vez que ésta, mediante las oportunas gestiones políticas, fuera nuevamente instaurada. En sus decretos básicos y fundacionales no preveía el apoyo a las fuerzas guerrilleras y a los planes de invasión que constituían una alternativa nunca abandonada, con centro geográfico en Toulouse. La declaración de intenciones era, sin lugar a dudas, otra: disponer del apoyo y la colaboración de los organismos internacionales para hacer inviable la continuación del régimen de Franco, y reimplantar el ejército desalojado del país en 1939 como fuerza fundamental de defensa de la República. Sin embargo, esto no fue óbice para que el Ministerio de Defensa Nacional mantuviera bajo análisis las fuerzas de guerrilleros y maquis en el sur de Francia y les prestara, en términos generales, su

\footnotetext{
${ }^{5}$ En el Archivo del General Rojo, en el Archivo Histórico Nacional en Madrid, se encuentra la correspondencia de Vicente Rojo durante el período del exilio, y en ella es posible advertir la contrariedad con que asumieron el nombramiento de Saravia gran parte de los militares del entorno de Vicente Rojo.

${ }_{7}^{7}$ AHN, Sección Diversos, Archivo del general Rojo, Caja 38, Carpeta 1, Carta de Patricio Azcárate al general Rojo. fechada en México D.F., el 6 de octubre de 1945.
} 
ayuda, aunque siempre bajo el principio de que aquellas actividades no eran el objetivo prioritario.

Con estas premisas, Juan Hernández Saravia maduraba la estructuración de un Ministerio flexible y limitado por las circunstancias en que había de trabajar, cuyo objetivo inicial quedaba definido en los decretos de 27 de noviembre de $1945^{8}$. La primera tarea para la constitución de un ejército preparado en el exilio era la elaboración de un censo de militares que permitiera conocer la situación y las aptitudes de los militares exiliados para esbozar un encuadramiento inicial.

Saravia hizo al general Leopoldo Menéndez - que había sido su colaborador y compañero, desde los tiempos del Gabinete Militar del Ministerio de Azaña en 1931 - la propuesta de ocupar el puesto de subsecretario del Ministerio desde el mismo momento de su nombramiento, en agosto de 1945. Menéndez mantenía contactos con los militares cercanos a Rojo a los que les parecía improcedente su colaboración en un Gobierno de cariz netamente republicano. Menéndez, que residía en Colombia, desde su salida de Francia en 1939, acudió a México D.F., abandonando la cátedra que ocupaba en la Escuela Superior de Guerra de Bogotá, para ser nombrado subsecretario del Ministerio de Defensa el 20 de diciembre de 1945.

A principios de diciembre de 1945, Juan Hernández Saravia era uno de los primeros ministros que preparaba su instalación en París, a la que seguirían la de la totalidad del Gobierno, animada por las nuevas perspectivas internacionales que aconsejaban la ubicación en la capital francesa. Parecía inminente el reconocimiento del Gobierno por parte de las autoridades galas, a pesar de lo cual, éste no llegó nunca. Sin embargo, el movimiento de traslado que había iniciado el ministro de Defensa pudo consumarse al completo por una autorización explícita del Gobierno francés que les concedió las bases necesarias para su funcionamiento autónomo en París, entre las que se incluía la instalación de la sede del Gobierno en las oficinas situadas en el 35 de la avenue Foch, y la cesión de algunos departamentos de la Cité Universitaire para su utilización como viviendas por parte de los miembros del Gobierno.

En México D.F., Juan Hernández Saravia firmaba su última orden ministerial el 4 de diciembre de 1945, designando al coronel jefe de su gabinete militar, Manuel Fe Llorens como encargado de la coordinación con el ministro y de dirigir las tareas del Ministerio en México, mientras se establecía la definitiva instalación de éste en París ${ }^{9}$. El 6 de diciembre, Saravia iniciaba su viaje rumbo a París, haciendo escala en Washington y Londres. Al llegar a París recibió la noticia de la enfermedad de su mujer, Milagros de Rojas Feingenspan, que había permanecido junto al resto de su familia en Marse-

${ }^{8}$ FUE, Fondo París, Leg. 456.3, Decretos de 27 de noviembre de 1945 del Ministerio de Defensa Nacional de la República Española, en México D.F.:Leg 896-6, Orden Ministerial de 27 de noviembre de 1945.

${ }^{9}$ FUE, Fondo París, Leg. 896-6, Orden Ministerial firmada en México D.F., a 4 de diciembre de 1945. 
Ila, esperando la vuelta de Saravia ${ }^{10}$. Por este motivo, hubo de salir precipitadamente a Marsella donde, tras la notable recuperación de su esposa, que padecía un enfisema pulmonar con complicaciones cardíacas, realizó las gestiones para el traslado de su mujer y su hija menor, Elisa, a París. El resto de su familia - sus hijos y nietos- permanecían en Marsella.

\section{PARÍS: NUEVOS VIENTOS PARA LOS DESTERRADOS.}

En los últimos meses de 1945 y los primeros de 1946 se produjo una modificación sustancial del ambiente en el que la comunidad de exiliados desarrollaba su vida. El gélido invierno de 1946 en París ${ }^{11}$ acogió con calidez a los miembros del Gobierno que fueron llegando, poco a poco, a la capital francesa. Ya desde marzo de 1945, el Gobierno francés había establecido una asignación anual considerable ${ }^{12}$ para el establecimiento en París de una Oficina Central de Refugiados Españoles. La ubicación en la avenue Foch de la sede del Gobierno de la República en el exilio y la concesión de nuevas subvenciones y créditos por parte del Estado francés eran una muestra del apoyo explícito — nunca reconocido legalmente- a las autoridades del exilio español.

La nueva consideración de los exiliados españoles alcanzaba a las manifestaciones públicas, hasta el punto de que la celebración del XV aniversario de la República se convirtió en un homenaje cultural al republicanismo español con una recepción en la sede de la avenue Foch en la que participaron miembros de la política francesa como Leon Blum, Paul Boncour, Edouard Herriot, representantes de varios partidos políticos de izquierda, miembros de la intelectualidad como Jean Sarrailh, Albert Camus y François Mauriac, entre otros, y simpatizantes de diversas nacionalidades que, después de los difíciles momentos de la II Guerra Mundial, se prestaban al reconocimiento manifiesto del papel público de los republicanos exiliados.

Para Juan Hernánez Saravia, los nuevos tiempos supusieron una transformación radical en su modo de vida. Desde su salida al exilio, acompañado por nueve miembros de su familia - su mujer, sus cinco hijos, su yerno y dos nietos- el asunto económico se había convertido en una prioridad permanente. A pesar de la constante mediación en favor suyo de los dirigentes republicanos ante las instituciones de ayuda, sobre todo del presidente Azaña, Saravia hubo de esperar varios meses para recibir un

\footnotetext{
${ }^{10}$ Fundación Luis Bello, Fondo Santos Martínez Saura, Caja 5, sobre 1, Carta de Juan Hernández Saravia a Santos Martínez Saura, fechada en Marsella el 19 de diciembre de 1945.

${ }^{11}$ Podemos encontrar una panorámica brillante del ambiente de la comunidad republicana, y concretamente del que se vivía en torno al Gobierno de la República en Virgilio Botella Pastor, Entre Memorias: las finanzas del gobierno republicano español en el exilio, Sevilla, Biblioteca del exilio, 2002, pp. 118-121.

${ }^{12}$ La asignación consistió en 2.100.00 francos anuales, en Alicia ALTED, «Ayuda humanitaria y reorganización...», p. 208.
} 
subsidio por parte del S.E.R.E. al que renunció casi de inmediato, considerando que la actuación de esta organización — controlada por Negrín y sus seguidores - no era respetuosa con la figura del ex presidente de la República, Manuel Azaña. La J.A.R.E. se hizo cargo entonces de la subvención mensual de Juan Hernández Saravia, pero la precariedad económica le acompañó durante toda la Guerra Mundial. A pesar de que lo intentó en repetidas ocasiones, no consiguió el permiso para salir de Francia y hubo de soportar, junto con su familia, la amenaza constante de extradición que se cernía sobre él, sobre todo después de que Alemania ocupara la totalidad del país. En Eguilles -en los alrededores de Marsella, en primer lugar, y en Marsella, más tarde, compartió casas con amigos y pensiones de españoles, tratando de mantener el contacto con la comunidad republicana por correspondencia y por los tímidos enlaces que podía mantener en la ciudad portuaria donde veía, con frecuencia, la salida de compañeros más afortunados hacia las tierras americanas.

El cambio de actitud respecto al grupo de exiliados españoles y su participación como ministro en el Gobierno del doctor Giral incidieron en una modificación sustancial de su modo de vida. El traslado a París permitió abandonar las pensiones en las que habian vivido en Marsella e instalarse en las dependencias que el Gobierno francés había habilitado como vivienda para los miembros del Gobierno en la Cité Universitaire. En ellas se alojaba también el presidente Giral. Aquéllas eran viviendas con condiciones suficientes y representaban un cambio que incluso permitió una mejoría en el estado de salud de su mujer, Milagros ${ }^{13}$. Desde su puesto, la asistencia a reuniones y recepciones públicas - sobre todo las ofrecidas por los embajadores y representantes de los países que habían reconocido a la República Española- que le mantenían en contacto con el resto de los republicanos y con la clase política francesa era una de las grandes recompensas después de los años de forzada lejanía de la vida pública. Por fin, dejaban de ser proscritos y necesitados en territorio extraño. Pero aquello no era suficiente. En último término, el objetivo añorado era la vuelta a España, la recuperación de la República en territorio nacional y el ofrecimiento, como homenaje póstumo, de esos logros a la memoria de Manuel Azaña ${ }^{14}$.

Los primeros meses de 1946 no sólo trajeron los tardíos de apoyos de los intelectuales y políticos en territorio francés: hubo, además, una toma de partido a favor de la cuestión española en el terreno internacional. Desde finales del año anterior, Francia venía demandando a las potencias aliadas

\footnotetext{
${ }^{13}$ Saravia se asombraba de la circunstancia de tener una vida confortable, con habitaciones caldeadas por la calefacción en aquel frío invierno, en Fundación Luis Bello, Fondo Santos Martínez Saura, Caja 5, Sobre 1, Carta del Ministro de Defensa Nacional de la República Española a Santos Martínez Saura, fechada en París, el 14 de febrero de 1946.

${ }^{14}$ Esa idea reiterada, acorde con el temperamento y la ideología de un optimista Juan Hernández Saravia, aparece en todas las cartas de su epistolario con Santos Martínez en FLB, SMS, Caja 5, sobre 1.
} 
un cambio de actitud respecto al problema de España. Las últimas actuaciones represoras del régimen de Franco, con el fusilamiento en febrero de diez guerrilleros españoles, motivaron el cierre de la frontera francesa y la intención de acudir al Consejo de Seguridad de la O.N.U. en demanda de una solución para el problema. Francia se encontró sola en esta batalla y abandonó su propósito, dejando a Polonia como principal portavoz en las denuncias de la comunidad internacional hacia el régimen de Franco. El Gobierno de José Giral tomó dos medidas inmediatas frente a la nueva situación: en primer lugar, una actuación en el plano internacional que pretendía recabar el máximo reconocimiento internacional y demostrar la amenaza que para la estabilidad internacional suponía el mantenimiento de la España franquista. En segundo lugar, una ampliación significativa del espectro político integrado en su Gobierno. La incorporación de Alfonso Rodríguez, en representación de la O.R.G.A., el comunista Santiago Carrillo y el independiente Sánchez Guerra como ministros sin cartera y la ocupación del ministerio de economía por el socialista Enrique de Francisco, daban forma a una remodelación que pretendía, asumiendo las bajas de Fernando de los Ríos y Nicolau d'Olwer, implicar a un mayor número de fuerzas políticas en el nuevo compromiso republicano.

Juan Hernádez Saravia valoró positivamente la polémica incorporación de comunistas y nacionalistas al nuevo Gobierno. Prieto - y, en menor medida, Largo Caballero, que se encontraba en la fase final de su vida, por un importante problema renal- se opuso a la entrada de los nuevos miembros, pretendiendo vetar a los comunistas ${ }^{15}$. Pero la remodelación salió adelante, en el intento de presentar un frente unido - que, en la práctica, distaba mucho de existir - ante la legalidad internacional.

\section{LA LABOR DEL MINISTERIO DE DEFENSA: 1945-1946.}

El nuevo ministro de Defensa, que había comenzado su tarea en la capital mexicana, bajo los principios emanados por el nuevo Gobierno, dirigió sus primeras actuaciones a la estructuración del propio Ministerio. Los efectivos del ejército se estructurarían en dos zonas: una en América, que sería dirigida por el general Franciscc Llano de la Encomienda, en calidad de presidente de la Comisión Organizadora de las Fuerzas Militares de Tierra, Mar y Aire; y otra zona en Francia, países de Europa y África del Norte, dirigida por el general Mariano Gámir Ulibarri, también en calidad de presidente de la Comisión Organizadora. Cada comisión estaría apoyada por tres corone-

${ }_{15}$ «Pues bien, a pesar de la personalidad y de la influencia de estos señores (Prieto y Largo Caballero), el PSOE se mantiene firme en su apoyo al Gobierno y si hace falta dar entrada en el Gobierno a quien sea, ante la razón suprema de restaurar, continúar la República, harán el sacrificio que sean necesario para ello» en FLB, FSMS, Caja 4, sobre 1, carta de Juan Hernández Saravi a Santos Martínez, fechada en París, el 14 de febrero de 1946. 
les asesores y un Estado Mayor como órgano auxiliar de mando y tendría por tarea primordial censar a los efectivos militares dispersos por su ámbito de actuación y analizar su capacidad real para desempeñar el empleo que tuvieron en la República. Los generales que resultaran localizados quedarían a disposición inmediata del ministro de Defensa para su incorporación en cualquier comisión o tarea que éste pudiera encomendarles, mientras los coroneles estarían bajo el mando del general jefe de la zona.

En la filosofía de la integración del personal militar, quedaba pendiente el planteamiento de cuál sería el papel que tendrían en el nuevo ejército los hombres que habían prestado su servicio durante la contienda como integrantes de las milicias. Juan Hernández Saravia impartió instrucciones concretas a los jefes de las comisiones para la incorporación en el Estado Mayor de un jefe u oficial de milicias, pero, en todo momento, prevaleció la idea de la recuperación del ejército profesional de exiliados. La incorporación de un jefe de milicias en el Estado Mayor de las comisiones era un guiño a los partidos políticos, un intento de acercar posiciones - similar a los que propuso Juan Hernández Saravia durante su ministerio en los albores de la Guerra Civil- que no llegó a producirse. En la Comisión Europea, el general Gámir Ulibarri declinó la posibilidad de sugerir el nombramiento, argumentando que la carencia de formación teórica militar de los jefes milicianos y su propia condición de profesional le impedían escoger a ninguna persona para su designación ${ }^{16}$. En realidad, el decreto de definición de la tarea del Ministerio y la definición de tareas de las comisiones estaban dirigidos al control y encuadramiento del personal militar profesional, con vistas a su próxima utilización como ejército de la República. Los jefes y oficiales procedentes de milicias, por su parte, tampoco exhibieron un gran entusiasmo ante su incorporación a las órdenes de un Gobierno que pretendía ser un instrumento político en el que no se sentían representados.

La misión principal de las comisiones era la formación de los escalafones del personal militar disponible y la constitución de mandos y cuadros de las fuerzas militares con la intención de esbozar una estructura utilizable en un futuro próximo. Para ello, deberían localizar a los militares - cuyo deber, a título particular, era ponerse a disposición de la República- y examinar su documentación para acreditar su grado, cargo y empleo militar en la República. Una vez efectuada la comprobación documental, se sometería a los militares a un examen físico que demostrara la capacidad de desempenar el puesto adquirido y se propondría una formación que, en breve, estaría en disposición de ofrecer el Ministerio de Defensa, mediante la organización de cursos y pruebas de capacitación. Finalmente, la Comisión establecería el encuadramiento del militar, atribuyéndole el empleo que considerara adecuado.

${ }^{16}$ FUE, Fondo París, Leg. 32-10. 
Se establecían las remuneraciones para el personal del Ministerio y las comisiones, las cuales venían a paliar, en un buen número de casos -entre los cuales se encontró Juan Hernández Saravia- las graves deficiencias económicas que arrastraban los militares, sobre todo los de mayor edad, desde su salida al exilio.

En enero de 1946 se hallaban constituidas en su integridad las dos comisiones, con la participación de un buen número de militares: en la comisión americana, participaban como asesores los coroneles Aureliano Álvarez Coque y Carlos Núñez Maza y el almirante Ángel Rizo, y como integrantes del Estado Mayor, los coroneles Mariano Salafranca -que falleció ese mismo año, en los límites de la precariedad-, Rafael Sánchez Paredes, Rafael Sierra Mollá y Vicente Ramírez. En la Comisión para Europa y África del Norte, participaban en el consejo asesor los coroneles Martínez Vallespín, Antonio Domínguez Olarte y el contralmirante Fuentes, y García Carnero, Ángel Hernández del Castillo, Antonio Urzaiz y el capitán de navío, Monreal, como componentes del Estado Mayor ${ }^{17}$.

En el desarrollo de su actividad, la comisión europea se mostró más activa, tratando de cubrir las etapas que le habían sido encomendadas por el ministro. La comisión mexicana se limitó, prácticamente, a la resolución de los expedientes del personal que se había puesto a disposición del Gobierno ${ }^{18}$ y a la elaboración de algunos folletos divulgativos de las nuevas estrategias militares, como única actividad formativa. Por añadidura, eran conocidas en los medios militares las enormes desavenencias que existían en México y en América, fruto de las discrepancias que existían entre los sectores negrinistas, que dirigían los hasta entonces politizados centros y asociaciones militares, y los partidarios del Gobierno que acataban la prohibición de que los militares realizaran actividades políticas ${ }^{19}$.

Juan Hernández Saravia inició una ronda de contactos con los partidos políticos y centrales sindicales españolas en el exilio, representados por Izquierda Republicana, Unión Republicana, Partido Comunista, Partido Socialista Obrero Español, Ezquerra Catalana y C.N.T. ${ }^{20}$, con el propósito de involucrar a la dirección de los partidos en la tarea llevada a cabo por su Ministerio. La serie de contactos, que se cerró con el apoyo de la práctica totalidad de las organizaciones políticas — con algunas excepciones, en que la

\footnotetext{
${ }^{17}$ FUE, Fondo Paris, Leg. 33-3 y 456.3

${ }^{18}$ Las actas de la comisión americana, durante todo el año 1946 y hasta julio de 1947, recogen casi en exclusiva la resolución de expedientes de personal en las que mayoritariamente hay encuadramiento de militares profesionales, y en menor medida, procedentes de milicias, en FUE, Fondo París, Leg. 894-4.

${ }^{19}$ Las cartas entre militares recogen constantemente esats tendencias. «El espectáculo de nuestra desunión allí (México) es deplorable y completamente negativo por los partidismos políticos que todo lo envenenan", en FUE, Fondo París, Leg. 456-3, Carta de Manuel Fe a Mariano Gámir, fechada en París, el 3 de octubre de 1946.

${ }_{20}$ FUE, Fondo París, Leg. 931-3, carta del ministro de la Defensa a los partidos políticos, fechada en Paris, el 25 de octubre de 1946 y respectivas contestaciones.
} 
colaboración prometida fue más formal - pretendía, en primer lugar, el reconocimiento de la legitimidad del Gobierno y la ratificación explícita de que éste constituía la única autoridad competente en materia de asuntos militares. Saravia sugería, además, la posibilidad de que cada partido designase un enlace con el Ministerio, quien sería el encargado de transmitir la información militar que el partido llegara a poseer, tanto relativa al interior de España como al exilio. La disposición inicial de los partidos y organizaciones fue, a grandes rasgos, favorable. En la práctica, la colaboración quedó prácticamente reducida a la designación de algunos enlaces y el mantenimiento de contactos, lo cual era, en gran parte, objetivo prioritario de un entramado que pretendía excluir de los medios militares a las cuestiones políticas.

En la comisión europea, Gámir Ulibarri exhibió importantes dosis de actividad y personalidad suficiente para llevar a cabo una tarea en la que creía con firmeza. Desde su primer saludo a todos los militares de su zona, expone su convencimiento de que las nuevas circunstancias internacionales conducirán a la vuelta a España y, por ello, el ejército debe mantenerse movilizado y dispuesto. En España, habían perdido sólo una batalla, pero en la Guerra Mundial se había ganado definitivamente la guerra, con el triunfo mundial de la democracia ${ }^{21}$. La comisión avanzó en su trabajo de censado y encuadramiento militar, aunque hubo de extender su plazo de actuación durante todo el año 1946.

En la zona europea, la supervisión del ministro fue mucho más directa a pesar de que la sede de la comisión se encontraba en Toulouse y la del Gobierno en París - y permitió conceder una importante dimensión, radicalmente diferente a la que tuvieron en México, a los centros culturales de militares republicanos que quedaban bajo la dirección de Juan Hernández Saravia, con el apoyo de un consejo directivo y la intención de promover en ellos la capacitación y preparación de los militares y el mantenimiento de lazos de cohesión entre el colectivo. Los centros militares tuvieron en Europa una importancia práctica en el mantenimiento de un grado de relación entre los miembros del ejército en el destierro. Su tarea formativa y educativa quedó, en mayor medida, truncada por las dificultades que planteaba el proyecto. Se estableció la creación y reordenación de centros culturales militares en las localidades de París, Burdeos, Toulouse, Perpiñán, Marsella, Casablanca, Orán y Bizerta, los cuales centralizarían a los núcleos de población cercanos $^{22}$ y con ellos se consiguió, en último término, un replanteamiento de la imagen que los militares desterrados tenían en la Europa de posguerra.

27UE, Fondo París, Leg. 32-10, Carta de Mariano Gámir a todos los militares del ejército de la República española en Francia, países de Europa y norte de África.

${ }^{22}$ La estruturación fue minuciosamente elaborada y puede consultarse en FUE, Fondo París, Leg. 3210, Anexo sobre la reorganización del ejército de la República y Reglamento de los centros culturales de los militares. 
En el ámbito de la formación de los militares, también se mostró más activa la comisión europea que sometió a la consideración del ministro varios proyectos ajustados a la realidad, condicionados por la gran dispersión de los militares y la falta de fondos para la ejecución de actividades formativas presenciales. En Europa hubo conferencias y reuniones formativas frecuentes y, sobre todo, se publicaron folletos que condensaban los avances más recientes en la táctica militar surgidos en la guerra internacional.

A pesar de que fue en el terreno de los contactos con la resistencia española donde la comisión europea pudo mostrarse más práctica y efectiva, por su cercanía al lugar de los hechos, su actuación estuvo siempre condicionada por las directrices emanadas por el Gobierno y el ministro de Defensa. $Y$ sin lugar a dudas, esta era la postura de mayor controversia en los planes de actuación del Ministerio.

Para el Gobierno, el objetivo prioritario era la recuperación de la República para España y la caída del régimen de Franco mediante la presión internacional. Las acciones en el interior de España, necesariamente marcadas por su clandestinidad, debían considerarse como puntuales y su dimensión no debía poner en peligro el prestigio internacional de las instituciones republicanas. Por otra parte, subsistía la tradición de una resistencia española asociada a la francesa durante el período de la Guerra Mundial, monopolizada ideológicamente, como ya hemos visto, por el Partido Comunista y su actuación, siempre con un importante grado de independencia, podía poner en entredicho los cauces apolíticos y legitimistas por los que el Gobierno pretendía llevar el camino de sus tareas. Estas consideraciones podían hacer inviable la colaboración del Gobierno con los grupos que mantenían una resistencia clandestina activa en el interior de España, pero existían otra serie de argumentaciones que movían a la necesidad de atender estos movimientos. En primer lugar, su conocimiento e intento de coordinación conllevaba, en sí mismo, un intento de control que hacía revestir al ministro de un cierto barniz de legitimidad, también en la resistencia clandestina. En segundo lugar, suponía un deber casi moral atender y apoyar a aquéllos que ponían su vida en peligro por restaurar la realidad de la República.

Juan Hernández Saravia preiendió conciliar las dos tendencias, procurando hacer prevalecer el cariz legitimista de las actuaciones militares. No obstante, hubo apoyos a la resistencia y proyectos de organización de un mando único para los grupos armados del interior y los que intentaban acciones desde Francia. En esta tarea, destacó la comisión europea, proponiendo fórmulas de actuación y estableciendo coberturas a los grupos de guerrilleros. En abril de 1946, el jefe de Información del Estado Mayor de la Comisión para Europa, Ángel Hernández del Castillo, proponía una serie de directrices de colaboración en las que aún no se daba por sentado el apoyo práctico a la resistencia española por parte del Gobierno: «Caso que nuestro Gobierno tome de un modo efectivo el carácter de Gobierno de la Resistencia española, (será necesario) estrechar fuertemente la coordinación de 
la misma y maquis del interior para conseguir un bloque compacto y con directrices determinadas exclusivamente por el Gobierno "23. La contestación de Saravia, en mayo del mismo año, consideraba el proyecto en vías de realización.

Los servicios de espionaje -más correcto sería decir contraespionaje, ya que estaban centrados en las investigaciones de agentes franquistas en Francia-, cuyo control para algunos era básico, no existían como tal en el Ministerio. Juan Hernández Saravia propuso el aprovechamiento de las informaciones de las autoridades francesas, las cuales debían ser sobradamente probadas. En los archivos de la República en el exilio aparece esporádicamente alguna información relacionada tanto con actividades aisladas de intentos de penetración desde Francia, como con el franqueamiento de la frontera por parte de elementos sospechosos de realizar labores de espionaje para el régimen de Franco ${ }^{24}$. La tarea de colaboración entre los Gobiernos francés y de la República española en el exilio se centró, no obstante, en la localización de los guerrilleros que habían colaborado en la resistencia francesa, agrupándolos por números y zonas para hacer cesión de esa información a los órganos del Ministerio de Defensa.

En junio de 1946 se produjo uno de los momentos álgidos en el ánimo de los componentes del Gobierno de la República en el exilio. Parecían inminentes las resoluciones favorables sobre España en los organismos internacionales. El ministro de Defensa se hizo eco de ello ordenando la elaboración de destinos, sobre el papel, de las distintas unidades creadas del ejército republicano, dentro del ejército franquista, para incautarse de las palancas de mando del ejército. La comisión europea llegó a hacer algunas designaciones, aunque sin tener en cuenta a los militares republicanos que aún se hallaban en España y a los que vivían en América, y sólo pudo contar con las fuerzas de los residentes en Francia, Túnez, Argelia y Orán. Se efectuaron nombramientos y grupos y se llegó a formar «equipos de personal que, a una orden del ministro, debían partir inmediatamente para incautarse de las palancas de mando de la Marina en los puntos vitales siguientes: Ministerio de Marina, base naval de Ferrol, base naval de Cádiz y base naval de Cartagena ${ }^{25}$ La marcha de los acontecimientos internacionales frenó completamente el proyecto.

En abril de 1946, el representante australiano de la O.N.U. había propuesto crear un Subcomité para los asuntos españoles que estudiara en qué medida el régimen de Franco ponía en peligro la seguridad internacional. José Giral hizo un enorme esfuerzo por presentar documentados los

${ }^{23}$ FUE, Fondo París, 32.10, propuesta de Ángel Hernández del Castillo, fechada en Toulouse, el 23 de abril de 1946.

${ }^{24}$ FUE, Fondo París, Leg. 931-3, Reseignements: A/S franchissement clandestin de la frontiére francoespagnole, de 17 de juillet 1946.

${ }^{25}$ FUE, Fondo París, Leg. 896-6 
graves incumplimientos de la legalidad que reunía en sí mismo el régimen de Franco. Junto al memorándum español, fueron presentados otros acusando al régimen de Franco y dos, el británico y el estadounidense, que no lo consideraban como una amenaza para la seguridad internacional. La opinión de Gran Bretaña evitó que el dictamen de la Subcomisión, a pesar de considerar que el régimen de Franco constituía un peligro internacional, incluyese ninguna acción decisiva contra Franco y posibilitó que no fuera fijada fecha para la restauración de las libertades políticas. La Subcomisión preparó un proyecto de Resolución, pero el voto negativo de la URSS frente a nueve votos- impidió que prosperase, con lo cual se prologaba el tiempo de decisión hasta octubre, cuando sería nuevamente incluido en los puntos de la Asamblea General de la O.N.U.

Nunca los anhelos de los republicanos habían estado más cerca de ser alcanzados desde que habían llegado al exilio, como lo demuestran los planes del Ministerio de Defensa de preparación para la entrada inmediata en España. Juan Hernández Saravia acusa la desilusión ante el nuevo panorama. «Efectivamente, el golpe de los ingleses, haciendo que no prospere el dictamen de la Sub-Comisión del Consejo de Seguridad ha sido muy duro para nosotros. Es posible que en un momento podamos mirar a Inglaterra como al Paraguay, pero creo que este momento se va a retrasar mucho y no hay que echarle toda la culpa a Inglaterra. ¿Por qué no se la echa usted también a Rusia? El emplear el veto, impidiendo que la resolución de la O.N.U. fuera efectiva no nos ha hecho mucho bien tampoco. ${ }^{26}$

El informe que Juan Hernández Saravia emitía en octubre de 1946, con motivo del primer aniversario de la constitución de su ministerio, quedaba profundamente marcado por el inicio de un nuevo tiempo. Se había disuelto la euforia de la esperanza. Al frente todavía del ministerio de Defensa, daba comienzo una época marcada por el desarrollo de su vida privada y por el progresivo avance de la enfermedad de su mujer, Milagros de Rojas, y la necesidad de buscar un futuro más halagüeño para sus hijos, quizá en México que, con el apoyo de otros amigos y compañeros exiliados como Santos Martínez Saura, se mostraba como la nueva tierra prometida. A Juan Hernández Saravia le asistía la última rebelde esperanza de que la República española no se hubiera convertido simplemente en un recuerdo y, a pesar de que inició los trámites para la consecución de los visados para la mayor parte de su familia, él quiso permanecer en París agotando sus últimas posibilidades ${ }^{27}$.

\footnotetext{
${ }^{26}$ FLB, FSMS, Caja 5, Sobre 1, Carta de Saravia a Santos Martínez desde París, fechada el 15 de julio de 1946.

${ }^{27}$ «He hecho tal propaganda «por México» que todos, chicos y grandes, se quieren ir allí (...) Aquí quedamos Milagro, Elisa y yo, dispuestos a resistir hasta última hora». El subrayado es de Saravia, en FLB, FSMS, Caja 4, sobre 1, Carta de Saravia a Santos Martínez sin membrete, con el sello de «El Ministro de la Defensa Nacional de la República Española» y la anotación de "Confidencial».
} 
En su informe ${ }^{28}$ moderadamente optimista en cuanto a los resultados conseguidos por el Ministerio, Juan Hernández Saravia insiste en la idea de la condición apolítica, al menos en la práctica, de los militares, la cual continuaba levantando polémica un año después de su publicación como orden. Considera prácticamente concluido, aunque con un cierto retraso motivado por las enormes dificultades que conllevaba, el trabajo de elaboración del censo, que se había convertido en objetivo prioritario del ministro. Se había organizado un importante grupo de acciones para la formación del personal militar como la publicación y difusión de folletos y su desarrollo en conferencias. La protección a militares mutilados, ancianos y enfermos había sido abordada, en primera instancia, por el Ministerio de Defensa, pero esa labor fue transferida al Ministerio de Emigración, por lo cual la función de Defensa quedó reducida a la tramitación de la solicitud de ayudas y a la aportación de los datos.

Se muestra el ministro especialmente satisfecho de la creación de un Servicio de Información, coordinado con las autoridades francesas, de la resistencia interna en España que había permitido, en primera instancia, aportar una información relevante para su presentación ante el Subcomité del Consejo de Seguridad de la O.N.U., considerando que es en el punto referido a la resistencia interior donde el Ministerio debe centrar sus esfuerzos futuros, censando a la gran masa de excombatientes republicanos que no pudieron salir de España, que prácticamente agrupaba la totalidad de los Ejércitos del Centro, Extremadura, Andalucía y Levante ${ }^{29}$ y convirtiéndose en el mando único para todas las acciones de resistencia en territorio español, tarea que aún no considera realizada.

El otcño de 1946 fue transformando los planes de futuro de los republicanos españoles. La situación había cambiado. El 12 de diciembre de 1946 la O.N.U. hacía efectiva su resolución excluyendo al Gobierno de Franco de sus organismos internacionales. Sin embargo, no establecía ninguna medida inmediata de presión. La resolución no suscitó las mismas consideraciones en todos los republicanos. Para los socialistas, constituía un fracaso del Gobierno de José Giral y, como consecuencia de la fuerte crítica de uno de los partidos miembros del Gobierno, la crisis se abría en enero de 1947. El 26 de ese mismo mes dimitía José Giral. Juan Hernández Saravia dejaba de ser ministro y se negaba a participar en el nuevo gobierno presidido por Rodolfo Llopis. Desilusionado por la marcha de los asuntos y

${ }^{28}$ FUE, Fondo París, Leg. 931-4, Memoria de la gestión departamental en el primer año de su constitución, del Ministerio de Defensa, fechada en París, en octubre de 1946.

${ }^{29}$ Considera Saravia que en España quedaron prácticamente en su totalidad quince Cuerpos de Ejército, personal de Aviación y Marina. En efecto, la mayoría de los excombatientes que lograron atravesar la frontera franco-española por los pasos principales de Irún, Le Perthus y Portbou, pertenecían al Grupo de Ejércitos de la Región Oriental (G.E.R.O.), del cual fue Juan Hernández Saravia hasta el 27 de enero de 1939, fecha de su destitución. 
la desunión de los republicanos, rechazó un cargo que le era ofrecido por el nuevo ministro de Interior y Defensa, Julio Just, e inició los trámites necesarios para marchar a México o a Venezuela ${ }^{30}$. Saravia valora los asuntos en España cada vez con mayor pesimismo. La sucesión preparada por Franco, con el proyecto de ley de 28 de marzo, no solucionaba nada: "No creo que en España se produzcan en plazo breve acontecimientos que puedan sernos favorables -le escribe a Santos Martínez-. Hoy por hoy, me parece que la posición de Franco se afirma, pues por todos los síntomas, los monárquicos no tienen posibilidades y los republicanos, divididos lo mismo en el interior que en la emigración no representan fuerza de consideración. Por otra parte, la situación internacional es favorable a los falangistas. Por si fuera poco, la desdichada actuación del Gobierno ha hecho que no se hable ya de la República: la lucha entre Franco y el Gobierno republicano se ha convertido en pugna entre Franco y D. Juan, gracias al plan de capitulación que, francamente, orienta la política del Gobierno». ${ }^{31}$

A pesar de la decepción, que se sumó al dolor por la muerte de su mujer ${ }^{32}$, Juan Hernández Saravia hizo un último intento de superar la desilusión y aceptó participar en el nuevo Gobierno republicano que se formó tras la caída del presidido por Rodolfo Llopis. El 28 de agosto de 1947, Álvaro de Albornoz formaba su gabinete, incluyendo como ministro de Defensa a Juan Hernández Saravia. Continuó residiendo en París, acompañado únicamente por su hija Elisa -el resto de sus hijos y sus respectivas familias habían conseguido salir, tras muchas dificultades, hacia México-, negándose a abandonar la última esperanza depositada en el Gobierno de la República en el exilio. Ni las negociaciones que concluyeron en el Pacto de San Juan de Luz, ni la desaparición del Ministerio de Defensa - que fue sustituido por una oficina de información militar que también dirigió él- bastaron para hacer finalizar su colaboración con el Gobierno de la República. Pero su total confianza en el proyecto republicano había desaparecido desde la caída del Gobierno de José Giral. En julio de 1951, con la dimisión de Álvaro de Albornoz como presidente del Gobierno, Juan Hernández Saravia abandonaba toda responsabilidad política. Después de años de resistencia, México se ofrecía como la última alternativa: el abandono de la esperanza.

${ }^{30}$ FLB, FSMS, Caja 5, sobre 1, Cartas de Juan Hernández Saravia a Santos Martínez desde París, de 13 y 15 de febrero de 1947.

${ }^{31}$ FLB, FSMS, Caja 5, sobre 1, Carta de Saravia a Santos Martínez desde París, fechada el 24 de abril de 1947.

${ }^{32}$ Milagros de Rojas Feigenspan falleció el 27 de julio de 1947, en Valladolid, cuatro dias después de que la familia organizara un dispositivo para su traslado a España desde París, donde la esperaba su hija mayor, Fernanda y su familia, quienes habian vuelto a España en agosto de 1939, acuciados por las penurias económicas. 


\section{CONCLUSIONES: LA REPÚBLICA ESPAÑOLA, UNA CUESTIÓN INTERNACIONAL.}

Las instituciones de la República en el exilio recuperaron su vigencia en 1945 como consecuencia de las nuevas relaciones internacionales establecidas tras el final de la II Guerra Mundial. Parecía lógico que quienes consideraban a la Guerra Civil española como la antesala del conflicto mundial plantearan que había llegado el momento de adaptar la situación política española al contexto mundial, ratificando el triunfo de las democracias. Las primeras fases del funcionamiento de la República en el exilio no constituyeron un anacronismo utópico y desfasado, sino el intento de aprovechar la coyuntura mundial favorable para restaurar la República por parte de los grupos políticos y de opinión que coexistían en el exilio. Este intento venía a tomar el relevo del esfuerzo que hasta ese momento habían venido protagonizando los movimientos de resistencia española, asociados a otra coyuntura mundial y al desarrollo de la Resistencia francesa durante los últimos tiempos de la Segunda Guerra Mundial. La República en el exilio sustituyó a U.N.E. y a sus métodos simplemente porque el momento histórico había cambiado. Los políticos trataron de sustituir -y en contadas ocasiones, dirigir- a los guerrilleros y la legalidad se presentó como bandera ante la comunidad internacional.

En ese panorama, la reconstrucción de un ejército para la República quedaba especialmente marcada por la dualidad existente entre la nueva legalidad internacional y el apoyo a las acciones, más o menos individuales, de corte clandestino y guerrillero. Juan Hernández Saravia, un militar profesional republicano de la órbita de Manuel Azaña, fue elegido por sus particulares características para esta tarea. Aportaba un profundo conocimiento del ejército español, de la situación en que habían quedado los profesionales en el exilio y de las enormes desavenencias que sufría el mundo militar, centradas esencialmente en la postura política de sus miembros. Desde esa perspectiva, el general Saravia encaró la responsabilidad de preparar un ejército para la República. En su actuación inicial apenas pesó el componente utópico. La recuperación de la República aparecía un objetivo inminente. Con graves disensiones internas entre los militares, salvando la dificultad de tener que intervenir en tres continentes, y con la necesidad de encontrar el punto adecuado en la relación con los movimientos de resistencia internos y externos, comenzó la andadura del nuevo ministro que, en 1945, creía firmemente en la inminencia de la vuelta a España.

Los hechos internacionales fueron dando al traste con la vigencia práctica de sus actuaciones. Es cierto que en octubre de 1946 se había logrado censar y preparar a un número importante de militares. Los trabajos de las comisiones habían permitido corregir algunas situaciones de precariedad. $Y$, en general, se había producido en los países de acogida una reconsideración de la figura del militar desterrado. Fue en el terreno de la dirección y control de las acciones protagonizadas por la resistencia donde se produjo 
un menor acierto, en parte motivado porque ése era el punto más controvertido en la postura del Gobierno. Pero desde mediados de 1946, los cambios en el panorama internacional fueron echando tierra sobre las ilusiones de los exiliados españoles. Juan Hernández Saravia continuó su tarea durante algún tiempo, ya consciente de que la etapa que se iniciaba era otra radicalmente distinta, en la cual la labor principal del Gobierno de la República en el exilio era mantenerse a sí mismo. El progresivo dibujo del mapa internacional dominado por la Guerra Fría convirtió al Gobierno de la República en el sueño utópico y nostálgico de un grupo de republicanos. Para entonces, Juan Hernández Saravia había perdido ya su confianza en el futuro y había abandonado toda participación en el proyecto. La República se esfumaba en el recuerdo, como la vida de muchos compañeros militares, exiliados, dispersos y repartidos por el mundo. 